non-psychiatric medical problem (Shapiro et al, 1984). Identification of this large population of untreated, but potentially treatable, group of depressed patients by primary care providers would help reduce the impact of this major health problem. Estimates of the failure rates of primary care physicians in the detection of depression range from $45 \%$ to $90 \%$ (Eisenberg, 1992).

In screening for depression in primary care and psychiatric settings, computers offer several advantages over both clinician-, and paper-and-penciladministered tests. Computer-administered tests are more reliable, due to the standardisation of administration. Computers are not hurried, and do not forget to ask pertinent questions. Computers reduce, or free, clinicians' time, making them cost effective and time efficient. Errors due to scoring or data entry are eliminated, and results can be scored and presented to the physician immediately. In addition, patients may be more likely to disclose information of a sensitive nature, such as suicide, to a computer (Greist et al, 1974).

With the increased use of personal computers, computer-administered applications will become increasingly more common in both psychiatry and general medicine. The availability of valid and reliable computer-administered measures for the assessment of depression can be a valuable tool in assisting the primary care physician with the identification and treatment of this disabling disorder.

EisenberG, L. (1992) Treating depression and anxiety in primary care: closing the gap between knowledge and practice. New England Journal of Medicine, 326, 1080-1083.

Greist, J. H., Gustafson, D. H., Stauss, F. F., et al (1974) Suicide risk prediction: a new approach. Life Threatening Behavior, 4, 212-223.

Hamitron, M. (1960) A rating scale for depression. Journal of Neurology. Neurosurgery and Psychiatry, 23, 56-62.

Kobak, K. A., ReYnolds, W. M., Rosenfeld, R. et al (1990) Development and validation of a computer-administered version of the Hamilton Depression Rating Scale. Psychological Assessment: A Journal of Consulting and Clinical Psychology, 2, 56-63.

Shapiro, S., Skinner, E. A., Kessler, L. G., et al (1984) Utilization of health and mental health services: three epidemiologic catchment area sites. Archives of General Psychiatry, 41, 971-978.

KENNETH A. KobAK

JOHN H. GreisT

Dean Foundation for Health, Research and Education 8000 Excelsior Drive

Madison, Wisconsin, USA 53717

WILLIAM M. REYNOLDS Psychoeducational Research and Training Centre University of British Columbia Vancouver, British Columbia

\section{Community Treatment Order in Australia}

SIR: The recent mauling by a lion of a young man in London with a chronic psychosis has quite rightly reopened the debate on the pros and cons of a Community Supervision (or Treatment) Order (CTO) as part of an amendment to the Mental Health Act.

Having recently returned (temporarily) from Victoria, Australia, where I worked for over two years in an increasingly community-orientated post near Melbourne, I would like to comment on the operation of their CTO which was introduced in the Victorian Mental Health Act (1986).

It soon became clear to me that the CTO was not used a great deal, but that most psychiatrists agreed that it had an important place in the community management of those patients with chronic psychoses who suffer from severe loss of volition and energy, lowered motivation, limited insight, and consequent poor cooperation with their treatment plans. The CTO is especially useful as a means of persuading patients to accept depot neuroleptics or some form of day care on a regular basis. It has very similar provisions to a Hospital Treatment Order, so that it is known from the outset by all concerned that if the patient is non-compliant he/she will be returned to hospital (revocation of the CTO) after receiving the written authority of the treating consultant.

There is, of course, an obvious potential for abuse, but interestingly this is not an issue that patients' rights groups have taken up with vigour. As with inpatients on Treatment Orders, there is the safeguard of automatic, regular review by the Mental Health Review Board (independent review tribunals). The latter's annual reports indicate very few instances of unjustified community 'detention'.

I would like to recommend close scrutiny of the Victorian CTO system in order to ascertain the extent to which it may be applicable and acceptable to the public and health professionals in Britain.

Lakeside Psychiatric Hospital

ANTHONY E. HARDMAN

\section{P.O. Box 63}

Ballarat

Victoria 3353

Australia

\section{Insight in psychosis}

SIR: I read with interest the study by David et al (Journal, November 1992, 161, 599-602) regarding measurement of insight in psychosis. While agreeing that concepts such as the relabelling of events as pathological, and the recognition of having a psychiatric or nervous illness are integral to the concept of 